\title{
Estimates of historic changes in total mortality and selectivity for Eastern Atlantic skipjack (Katsuwonus pelamis) from length composition data
}

\author{
Daniel Gaertner ${ }^{\mathrm{a}}$ \\ UMR EME, Institut de Recherche pour le Développement (IRD) CRH, BP 171, 34203 Sète Cedex, France
}

Received 12 February 2009; Accepted 13 May 2009

\begin{abstract}
Catch-at-size data of the eastern Atlantic skipjack were used to estimate changes in total mortality from 1969 to 2007 . We used a transitional model of mean length that generalized the Beverton-Holt mortality estimator to allow change in mortality rate under nonequilibrium conditions. Then, from homogeneous periods of time, lengthconverted catch curves were used to access qualitative changes in selectivity patterns for two surface fisheries (the baitboat fishery operating from Dakar, Senegal, and the European and associated purse seine fisheries). To explore the impact of catch on the mortality rate, a Bayesian change-point analysis was conducted on the catch time series to detect concomitant variation between mortality rates and catch. Finally, potential causes of these changes are discussed in relation to the implementation of new fishing technology, such fish aggregating devices (FAD). The general pattern depicted by total mortality is in agreement with previous knowledge on this fishery: a state of complete or practically complete exploitation during the nineties followed by the decrease in nominal purse seine fishing effort in the last decade, combined with the effect of a seasonal moratorium on FAD fishing operations. There was no evidence of a change in selectivity between the two contrasted periods of time considered: 1969-1979 and 1986-1999; the second period being characterized by the introduction of new technology onboard vessels. In contrast, the covariation over time between total catch and mortality rate three years later highlights the effect of the fishing pressure on the stock of eastern Atlantic skipjack.
\end{abstract}

Key words: Skipjack tuna / Mortality rate / FAD / Fishing strategies / Bayesian change-point analysis

Résumé - Estimation des changements survenus dans la mortalité et dans la sélectivité du listao de l'Atlantique Est (Katsuwonus pelamis) à partir des fréquences de tailles. Les captures par fréquences de taille du listao de l'Atlantique Est sont utilisées pour estimer les modifications de la mortalité totale survenues entre 1969 et 2007. Pour cela, nous avons utilisé un modèle de transition sur la taille moyenne qui généralise l'estimateur de mortalité de Beverton et Holt à des conditions de non-équilibre. Ensuite, à partir de périodes de temps homogènes, nous employons la courbe des captures en fonction de la taille pour estimer les changements qualitatifs de sélectivité pour deux pêcheries de surface (celle des thoniers canneurs opérant au large de Dakar, Sénégal, et celle des senneurs européens, ou assimilés). Pour analyser l'influence des captures sur le taux de mortalité, une analyse Bayésienne des points de rupture de la série temporelle des captures est réalisée afin de mettre en évidence des variations conjointes entre captures et mortalité. Les causes potentielles de ces modifications au cours du temps sont ensuite discutées à la lumière des connaissances sur l'introduction de nouvelles technologies de pêche, comme par exemple les dispositifs de concentration de poissons (DCP). L'évolution générale du coefficient de mortalité totale est en accord avec les connaissances acquises sur cette pêcherie : un état de pleine exploitation ou quasiment de 1990 à 1999, suivi par la chute de l'effort nominal au cours des dix dernières années, combiné avec l'effet du moratoire saisonnier sur les DCP. Il n'y a pas de preuve claire d'un changement de sélectivité entre 2 périodes de temps contrastées : 1969-1979 et 1986-1999; la seconde étant connue comme celle ayant bénéficiée de nombreuses innovations technologiques. En revanche, la covariation entre captures et mortalité 3 ans après, met en évidence l'impact de la pression de pêche sur le stock de listaos de l'Atlantique Est.

a Corresponding author: gaertner@ird.fr 


\section{Introduction}

Traditional stock assessment models have been difficult to apply to skipjack (Katsuwonus pelamis) because of certain key aspects of its biology. Skipjack spawns in an opportunistic manner throughout the year and over large areas, so recruitment is continuous but heterogeneous in space and time (Cayré and Farrugio 1986). This explains why cohorts cannot easily be identified. Furthermore, skipjack growth parameters vary with latitude (Bard and Antoine 1986; Gaertner et al. 2008). The catch-at-age matrix will, therefore, not be consistent because fish of the same age will exhibit different sizes depending on their past movement patterns. Another difficulty arises from the fact that skipjack tuna is often a secondary species, depending on the price differential and catchability of other target species. Consequently, estimation of the effective effort exerted on skipjack (e.g. effort proportional to fishing mortality) remains problematic, and catch rate may sometimes depict a different trend than abundance. In order to overcome these difficulties, promising new assessment methods that attempt to accommodate expert opinion and prior knowledge of the fishery and the biological characteristics of skipjack have recently been applied by the International Commission for the Conservation of Atlantic Tunas (ICCAT) on the two stocks of Atlantic skipjack. However, additional analyses of the trends in some fishery indicators provide simple evidence of changes in the state of the stock over time. In this context, estimating total mortality and gear-specific selectivity patterns from catch-at-length data can be a useful alternative to conventional approaches, and provide some insight on stock responses with regard to historic changes in fishing strategy.

Dramatic changes in fishing practices have been reported in the surface fisheries operating in the eastern Atlantic in the exploitation of skipjack since the early 1970s:

- Adoption of the "associated-school fishing mode" by baitboats operating from Dakar since the early 1980s. This fishing method consists of permanently maintaining the tuna school under the baitboat while catching fish every day (Fonteneau and Diouf 1994);

- Continuous introduction of new fishing technology onboard purse seiners (bird radars, drifting fish aggregating devices (FADs), supply vessels, GPS positioning buoys, tracking buoys, satellite information on environmental factors, sonar, echo sounders, purse winches, power blocks, purse seine size modifications, material used for the net, rail rollers, etc., Hervé et al. 1991; Fonteneau et al. 1999; Moron et al. 2001), whose impact on fishing power has been raised by French (IRD) and Spanish (IEO) scientists during the EU research program "ESTHER".

All these changes have resulted in an increase in the exploitable biomass of the skipjack stock and in skipjack catchability, as reflected by the pattern of the historic catch in the eastern Atlantic (Fig. 1). Total skipjack catches increased from the 1960 s to reach an average of $100000 \mathrm{t}$ in the early 1980s,

1 Gaertner D., Pallares P., 2002, Efficacité des senneurs thoniers et effort réels (ESTHER). Progr. No. 98/061. Union européenne, DG "Fisheries" (DG XIV), Bruxelles. Rapport scientifique [http://ec. europa.eu/fisheries/publications/studies/biological2004.pdf]

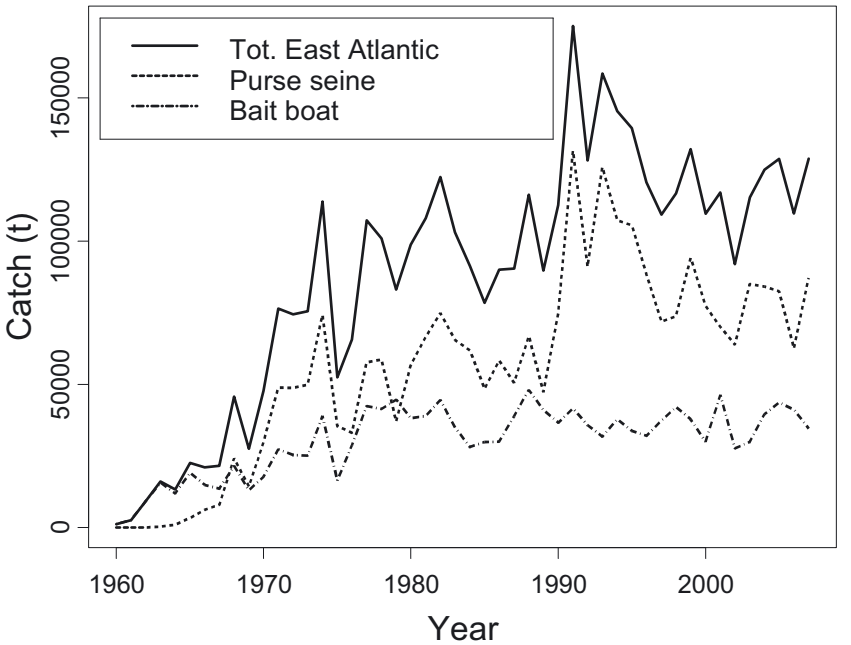

Fig. 1. Reported landings of skipjack in the eastern Atlantic using different fishing techniques from 1960 to 2007.

then reached their highest value in 1991 (175 $000 \mathrm{t}$ ). It should be noted that this period coincides with the massive use of FADs (Ariz et al. 1999). Since then, the catches of skipjack have shown a gradual decline, probably as a combined result of the decrease in nominal purse seine effort and the impact of moratoria for FAD fishing. In recent years, catches have remained stable at about 120000-130000 t.

With the aim of exploring the consequences of new fishing strategies on the stock of eastern Atlantic skipjack, this study was organized as follows: (1) change over time in total mortality rates $(Z)$ was estimated from mean lengths data in nonequilibrium situations; (2) from pooled frequency size data within homogeneous periods of time, length-converted catch curves were used to access qualitative effects on change in selectivity patterns, then (3) concomitant historic changes in catch, considered as reliable explanations for changes in mortality rates, were investigated with the aid of a Bayesian change-point analysis. Finally, potential causes of these changes were discussed in relation to the implementation of new fishing technology.

\section{Material and methods}

\subsection{Data}

As changes in fishing practices are better documented from the European and associated fleets, we considered catch-at$\mathrm{size}^{2}$ for the EC purse seiner fleets from Spain, France and associated flags (Guatemala, NEI-Etro, Netherlands Antilles, Morocco, Panama), from 1969 to 2007. Ghanaian purse seiners were not considered in this study, however, as Ghanaian purse seiner catch-at-length data is related to the difficulty in discriminating purse seine catch-at-size from pole and line data, since both types of fishing gear are commonly associated during fishing operations (Bannerman and Bard 2001).

${ }^{2}$ Catch-at-size data for tropical tunas are collected by the International Commission for the Atlantic Tuna (ICCAT), available at: http://www.iccat.int/accesingdb.htm 
In the case of baitboats, only those vessels operating from Dakar (Senegal) were considered (i.e., EC-France, EC-Spain and Senegal).

\subsection{Methods}

It is widely accepted that mean length of a fish population is inversely related to its total mortality rate. With this idea in mind, Beverton and Holt (1956) developed a functional relationship between mean length in the catch and total mortality rate $(Z)$ :

$$
Z=K \frac{(L \infty-\bar{L})}{(\bar{L}-L c)}
$$

where $L \infty$ and $K$ represent the conventional parameters of the von Bertalanffy growth curve, $L c$ represents the length at which fishes are fully recruited, and $\bar{L}$ the average length for fully-recruited fish.

However, this simple estimator requires some important assumptions: notably that recruitments are constant over time and that mortality rates are constant with regard to age and over time. Recently, Gedamke and Hoenig (2006) generalized the approach of Beverton and Holt to allow mortality rate to change in nonequilibrium situations.

From the simple expression of the mean length:

$$
\bar{L}=\frac{\int_{t c}^{\infty} N_{t} L_{t} \mathrm{~d} t}{\int_{t c}^{\infty} N_{t} \mathrm{~d} t}
$$

where $N t$ and $L t$ represent the abundance and body length of fish at age $t$, respectively, Gedamke and Hoenig (2006) stated that when a stock experiences a change in total mortality the mean length depicts a transitional phase before gradually approaching the new true value as the new equilibrium is reached. Thus, both in the numerator and in the denominator, the integrals should be broken down into a sum of two integrals respectively representing (1) fish recruited after the change in mortality (these fish having experienced only the second mortality rate) and (2) fish recruited before the change (and consequently exposed to the old and the new mortality rates). For example after a change in the total mortality from $Z_{1}$ to $Z_{2}$, the mean length in the population d years, after the change has occurred, is as follows:

$$
\bar{L}=\frac{\int_{t c}^{t c+d} R e^{\left[-Z_{2}\left(t-t_{c}\right)\right]} L_{t} \mathrm{~d} t+\int_{t c+d}^{\infty} R e^{\left[-Z_{2} d\right]} e^{\left[-Z_{1}\left(t-\left(t_{c}+d\right)\right)\right]} L_{t} \mathrm{~d} t}{\int_{t c}^{t c+d} R e^{\left[-Z_{2}\left(t-t_{c}\right)\right]} \mathrm{d} t+\int_{t c+d}^{\infty} R e^{\left[-Z_{2} d\right]} e^{\left[-Z_{1}\left(t-\left(t_{c}+d\right)\right)\right]} \mathrm{d} t}
$$

(for a general expression of mean length after multiple changes in the mortality rate, see Appendix 2 in Gedamke and Hoenig 2006).

Therefore, given a series of annual observations of mean length over time it is possible to estimate the original total mortality rate, the year in which it changed and the new mortality rate (and possibly even the next breaking date and resulting change in mortality rate, etc.).

Assuming that $\bar{L}$ is normally distributed, the maximum likelihood estimates of the parameters of interest are obtained by minimising the negative logarithm $(L L)$, which is as follows:

$$
L L=-\sum_{y=1}^{n} \operatorname{Ln}\left[\frac{m_{y}}{\sigma \sqrt{2 \pi}} e^{-\frac{m_{y}\left(\overline{L_{y}}-\overline{\text { Lpred }_{y}}\right)^{2}}{2 \sigma^{2}}}\right]
$$

where $\overline{L_{y}}$ and $\overline{\text { pred }_{y}}$ are the observed and the predicted mean length in year $y ; m_{y}$ and $\sigma$ are the number of fish and the standard deviation of lengths that are greater than $L_{c}$, respectively.

To handle a situation in which a change in mortality may have occurred prior to the beginning of the observed time series (a realistic assumption since catch of skipjack increased from $22000 \mathrm{t}$ in 1965 to $48000 \mathrm{t}$ in 1970, Fig. 1), Gedamke and Hoenig (2006) suggest to add an arbitrary mean length value for each year prior to 1969 (i.e., 1965-1968) along with a sample size of zero. As the sum of squares of residuals in the negative log likelihood equation is weighted by sample size, samples with values of zero will have no effect on the minimization ${ }^{3}$.

To access whether there have been multiple changes in the mortality rates of skipjack, different competing models (i.e., with different breaking dates and resulting number of parameters) were ranked according to the Akaike information criterion, adjusted for small sample sizes (AICc). The top-ranking model (i.e., smallest AICc) from this set was reported as the most parsimonious model, which is the model that best explains the variation in the data while using the fewest parameters (Burnham and Anderson 2002).

Under some strong equilibrium assumptions (constant recruitment and exploitation rate), equal vulnerability for fish larger than full recruitment size $(L c)$, constant natural mortality for all length groups in the catch, and considering that length data can be converted into age data using the inverse of the von Bertalanffy equation, the length-converted catch curve can be used to estimate the selectivity pattern. To minimize, insofar as it is possible, the violation of the equilibrium assumptions, catch-at-size data were pooled by homogeneous periods of time resulting from the application of the transitional model to mortality rates.

To make the traditional catch curve (Beverton and Holt 1956; Ssentongo and Larkin 1973) usable for length data (Sparre et al. 1989), we replace $t$ (age) of:

$$
L_{n} \frac{C(t, t+\Delta t)}{\Delta t}=\beta_{0}+\beta_{1}[t+\Delta t / 2]
$$

by $L$ (length).

With the one to one correspondence between the age interval $(t, t+\Delta t)$ and the length interval $(L 1, L 2)$, we can express the number of fish caught as $C(L 1, L 2)$. Let $\Delta t$ as the time it takes for a fish to grow from length $L 1$ to length $L 2$. From the inverse von Bertalanffy equation, we obtain:

$$
\Delta t=t(L 2)-t(L 1)=\frac{1}{K} \operatorname{Ln} \frac{L \infty-L 1}{L \infty-L 2} .
$$

\footnotetext{
${ }^{3}$ Calculations were performed with the aid of the SEINE software program: NOAA Fisheries Toolbox, 2008. Survival estimation in nonequilibrium situations (SEINE), Version 1.3 [http://nft.nefsc.noaa.gov].
} 
The linearized length-converted catch curve can be expressed as follows (Sparre et al. 1989):

$$
\operatorname{Ln} \frac{C(L 1, L 2)}{\Delta t(L 1, L 2)}=\beta_{0}+\beta_{1}[t(L 1)+\Delta t / 2] .
$$

Age interval $t(L 1)+\Delta t / 2$ midpoint can be approximated by: $t\left(\frac{L 1+L 2}{2}\right)=t 0-\frac{1}{K} \operatorname{Ln}\left[1-\frac{L 1+L 2}{2 L \infty}\right]$, where $t 0$ represents the theoretical age at which the fish would have had zero length.

Thus, the length-converted catch curve can be rewritten as:

$$
\operatorname{Ln} \frac{C(L 1, L 2)}{\Delta t(L 1, L 2)}=\beta_{0}+\beta_{1}\left[t\left(\frac{L 1+L 2}{2}\right)\right]
$$

with the slope $\beta_{1}=-Z$.

The regression analysis omits the length classes for which the fish were not considered fully recruited to the fishery $(L 2<L c)$, as well as large size classes approaching $L \infty$. It should be noted that using the fraction of the total catch corresponding to each length class leads to the same result as using the number caught (Restrepo et al. 2007).

Once the parameters of the linearized length-converted catch curve have been estimated, it is possible to extrapolate the straight line on the left hand side of the curve, and consequently to calculate the proportion of fish that are missing for length classes lower than $L c$, by estimating the ratio of observed $C(L 1, L 2)$ to predicted catch $C(\widehat{L 1, L 2})$ at each length class $(L 1, L 2)$ (i.e., $S(L 1, L 2))$ :

$$
S(L 1, L 2)=\frac{C(L 1, L 2)}{C(\widehat{L 1, L 2})},
$$

with $L 2<L c$, and then re-scaled so that the maximum is 1 .

Based on the fact that the ratio of the gear's catch to the total catch is proportional to the ratio of the gear's fishing mortality to the total mortality, gear-specific selectivity: $s_{g}(L 1, L 2)$ can be computed as the catch ratio (i.e., $R_{g}(L 1, L 2)$ multiplied by total selectivity (Restrepo et al. 2007):

$$
\begin{aligned}
R_{g}(L 1, L 2) & =\frac{C_{g}(L 1, L 2)}{\sum_{g} C_{g}(L 1, L 2)}, \\
s_{g}(L 1, L 2) & =S(L 1, L 2) R_{g}(L 1, L 2),
\end{aligned}
$$

then, re-scaled so that the maximum is 1 .

Assuming that the selection ogive follows a logistic curve, the length group at which $50 \%$ of the catch is recruited (L50) can be calculated directly from a reparametrized expression of the logistic equation:

$$
s_{g}(L 1, L 2)=\frac{1}{1+A_{g}^{(1-L 1 / L 50 g)}}(\text { Gaertner and Lalöe 1986). }
$$

In the present study, based on visual inspection of the linearized catch curve, Lc was fixed at $46 \mathrm{~cm}$ fork length. As growth of skipjack is known to vary with latitudes in the Atlantic Ocean (Bard and Antoine 1986; Gaertner et al. 2008), we used estimates of growth parameters obtained from tagging data in the eastern Atlantic area located to the south of $10^{\circ} \mathrm{N}$ latitude. This large area is considered representative of an area used for FAD fishing. For the sake of simplicity we applied the same values of growth parameters to the whole sizefrequency dataset. However, we selected estimates of growth parameters provided by the Faben's equation, since estimates of $L \infty$ from this model were more similar between northern and southern areas $(96.78 \mathrm{~cm}$ and $99.88 \mathrm{~cm}$, respectively) than growth estimates obtained from the combined likelihood approach (which provided more regional difference in growth rate; Gaertner et al. 2008). Consequently, the parameters used were $99.88 \mathrm{~cm}$ and 0.20 per year for the asymptotic average maximum length $L \infty$ and for the curvature parameter $K$, respectively; $t_{0}$ was fixed at 0 .

Once the mortality history of the eastern skipjack has been reconstructed, it makes sense to look for concomitant variations over time between catch and mortality rates then to evaluate the time delay between cause and consequence. To do this we analyzed the process of sudden changes in total catch at unknown dates, using a Bayesian analysis for change-point problems. Change-point analysis assumes a series of independent observations collected over time. At one or more points in time the mean may shift. Let $X_{1}, X_{2}, \ldots, X_{n}$ represent the data in time order. A simple change-point model can be written as follows:

$$
\begin{aligned}
X_{i} \sim p\left(x_{i} \mid \theta_{1}\right), & i=1, \ldots, t \\
X_{i} \sim p\left(x_{i} \mid \theta_{2}\right), & i=t+1, \ldots, n
\end{aligned}
$$

where the density $p(x \mid \theta)$ belongs to a known class of probability densities, e.g., $N\left(\mu_{1}, \sigma_{1}^{2}\right), N\left(\mu_{2}, \sigma_{2}^{2}\right)$; t is called the changepoint.

While frequentist procedures for change-point analysis estimate specific locations of change points, the Bayesian approach offers a probability distribution (i.e., the probability of a change point at each location in a sequence). The Bayesian change-point algorithm (hereafter, BCP) proposed by Barry and Hartigan (1993) assumes that from a sequence of $n$ independent random variables there is an underlying sequence of parameters partitioned into contiguous blocks of equal parameter values; the beginning of each block is said to be a change point.

In this study we used an R implementation of the Barry and Hartigan (1993) product partition model for the standard change-point problem using Markov Chain Monte Carlo implementation (Erdman and Emerson 2007) ${ }^{4}$. The MCMC implementation of this procedure estimates the posterior distributions of the change points and the posterior means (considered as constant within blocks).

\section{Results}

Different competing models (from 1 to 5 changes points) used for determining mortality rates from mean length data in nonequilibrium situations for eastern Atlantic skipjack (1969-2007) were ranked by AICc from lowest to highest, with the lowest value representing the best approximating model (Table 1).

\footnotetext{
${ }^{4}$ BCP package [http://lib.stat.cmu.edu/R/CRAN/].
} 
Table 1. Model selection for determining mortality rates from mean length data in nonequilibrium situations for eastern Atlantic skipjack (1969-2007), with (N breaks) number of change points in total mortality, number of parameters, (Nll) negative log-likelihood, (AICc) Akaike corrected information criterion for small-sample sizes, ( $\triangle \mathrm{AICc}$ ) Delta AICc, $\left(\mathrm{W}_{i}\right)$ Akaike's information criterion weight and approximate breaking dates. Models have been ranked from best to worst according to the Akaike weights $\left(\mathrm{W}_{i}\right)$.

\begin{tabular}{|c|c|c|c|c|c|c|}
\hline $\mathrm{N}$ breaks & Number of parameters & N11 & AICc & $\triangle \mathrm{AICc}$ & $W_{i}$ & Breaking dates \\
\hline 3 & 8 & 233.34 & 486.92 & 0 & 0.78 & $\begin{array}{l}1979-80, \\
1985,1999\end{array}$ \\
\hline 4 & 10 & 231.57 & 490.01 & 3.10 & 0.17 & $\begin{array}{l}1979,1985, \\
1992,1999\end{array}$ \\
\hline 5 & 12 & 229.30 & 493.00 & 6.08 & 0.04 & $\begin{array}{l}1968,1979- \\
80,1985, \\
1999,2005\end{array}$ \\
\hline 2 & 6 & 240.07 & 497.48 & 7.56 & 0.02 & 1980, 1999 \\
\hline 1 & 4 & 247.35 & 503.75 & 16.84 & 0 & $1979-80$ \\
\hline
\end{tabular}

Table 2. Summary statistics for the best model estimating mortality from mean length data in nonequilibrium situations for eastern Atlantic skipjack (1969-2007) when four different levels of mortality and three years of change are estimated simultaneously.

\begin{tabular}{lllll}
\hline Parameter & Estimate & SE & $t$-value & $95 \%$ confidence intervals \\
\hline$Z_{1}$ & 1.90 & 0.05 & 39.19 & 24.01 \\
$Z_{2}$ & 2.40 & 0.10 & 39.09 & $2.20-2.60$ \\
$Z_{3}$ & 2.84 & 0.07 & 33.26 & $2.10-2.36$ \\
$Z_{4}$ & 2.23 & 0.07 & 4794.14 & $1978.67-1980.33$ \\
Year of 1rst change & 1979.50 & 0.41 & 10633.17 \\
Year of 2nd change & 1985.00 & 0.19 & 5291.05 & $1984.62-1985.38$ \\
Year of 3rd change & 1998.80 & 0.38 & 9.27 \\
$\sigma$ & 55.01 & 5.93 & $43.05-67.00$ \\
\hline
\end{tabular}

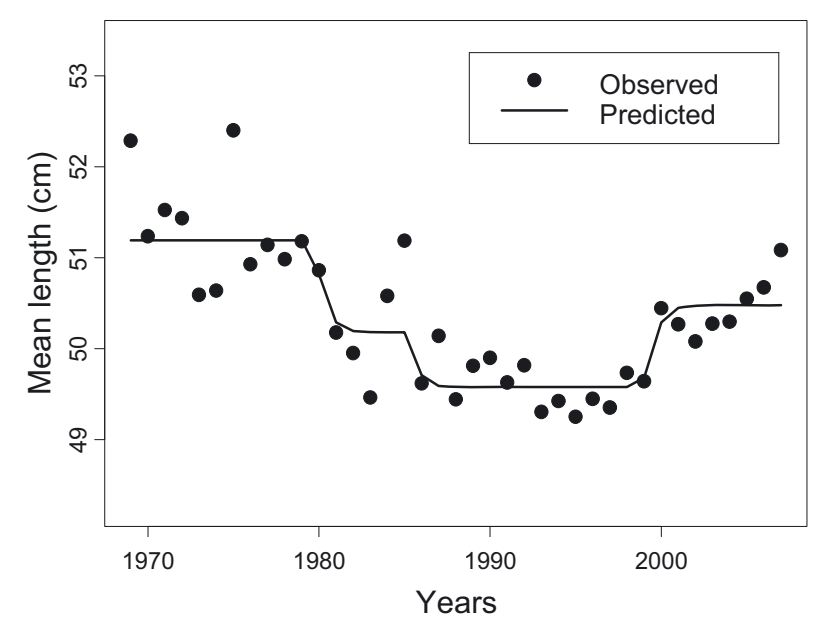

Fig. 2. Observed mean lengths of skipjack in the eastern Atlantic from 1969 to 2007 and values predicted by the transitional model of Gedamke-Hoenig in nonequilibrium situations.

The model with the highest weight of evidence was deemed the most plausible given the data and set of candidate models. No model had substantial support $\left(\triangle A I C_{c}<2\right)$, though the best approximating model had a weight of evidence $W_{i}$ of 0.779 . This parsimonious model, based on 3 breaking points over time, is $0.779 / 0.166=4.7$ times more likely to be the best explanation for changes in total mortality rates compared with a model with 4 breaking points.

The selected model fits well with the mean length of eastern Atlantic skipjack, even though the situation is less

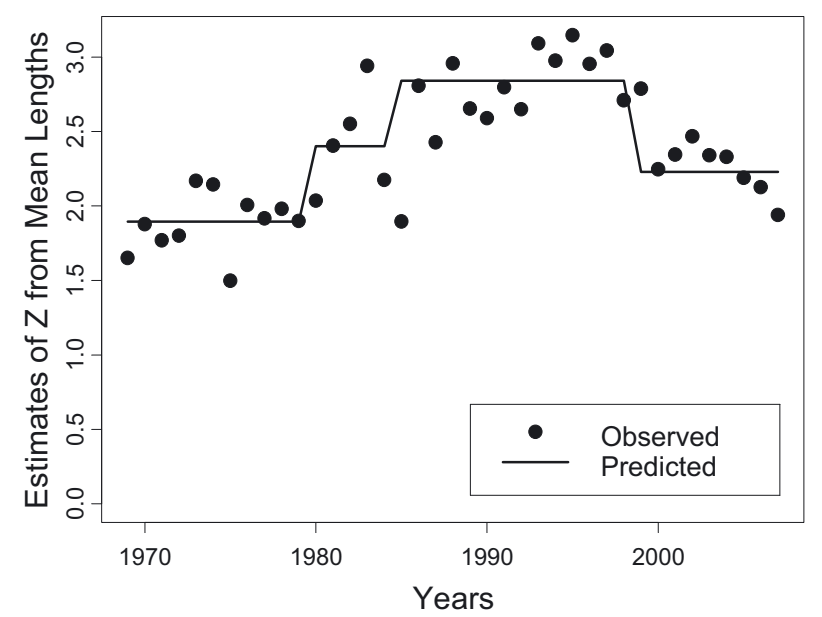

Fig. 3. Estimates of skipjack mortality rates $(Z)$ in the eastern Atlantic from 1969 to 2007. Observed values correspond to the Beverton-Holt estimator. Predicted line corresponds to the mortality estimates by the transitional model of Gedamke-Hoenig in nonequilibrium situations.

satisfactory in recent years (Fig. 2). The fitted values decrease gradually from $51.2 \mathrm{~cm}$ in the 1970 s to $50.2 \mathrm{~cm}$ at the beginning of the $1980 \mathrm{~s}$, then slip moderately to $49.6 \mathrm{~cm}$ in the late 1980s. Mean length stabilizes at this low level during the 1990s, and then increases at $50.5 \mathrm{~cm}$ after 2001.

The historic change in mortality rates is shown for the eastern Atlantic skipjack (Fig. 3). The clear downward trend until 2000 suggests an increase in mortality rate; this is followed, however, by a recovery in the recent period. Estimates from the 

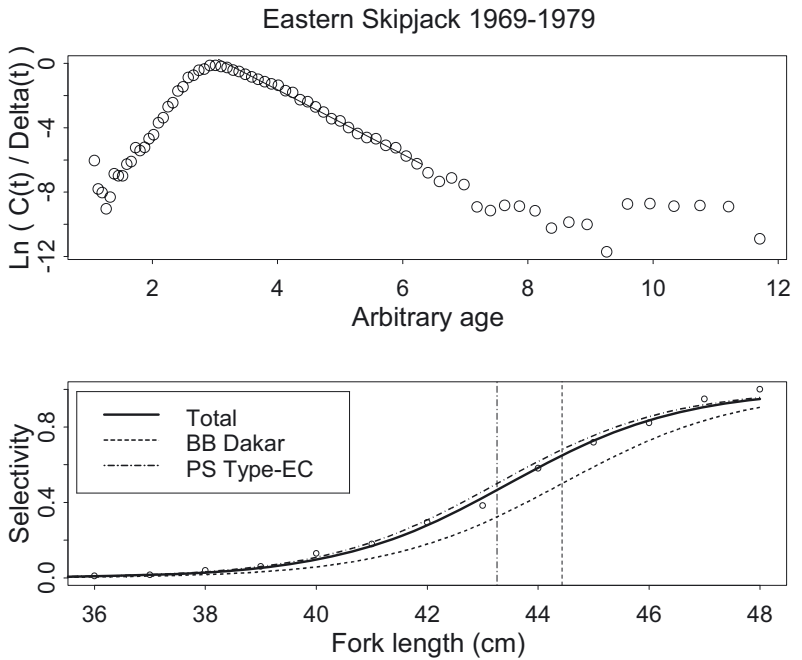

Fig. 4. Length-converted catch curve regressions (upper parts) and gear-specific selectivity patterns (baitboats operating from Dakar and EC-purse seiners and associated fleets) for the eastern Atlantic skipjack in the historic period (1969-1979). It is considered that little new fishing technology, if any, was introduced onboard tuna vessels during this decade.

conventional Beverton-Holt estimator are highly variable and range from 1.5 year $^{-1}$ in 1975 to 3.15 year $^{-1}$ in 1995 . Notice that mortality rates estimated by the model in nonequilibrium situations are consistent with Beverton-Holt estimates averaged over the same periods of time: 1.88, 2.42, 2.76 and 2.31 year $^{-1}$, respectively.

We obtain additional information about each change and a specific confidence interval for the year of change, indicating how well the year of change has been pinpointed (Table 2). Prior to the first change that occurred in $1979, Z$ was estimated at 1.90 year $^{-1}$. It rose to 2.40 year $^{-1}$ until 1985 , then remained stationary around 2.84 year $^{-1}$ during 1986-1999 before dropping to about 2.23 year $^{-1}$ over the most recent period.

Since stability in mean length was not achieved during some periods of time (e.g., in the recent years), selectivity patterns obtained from length-converted catch curve regressions were compared only for two contrasting periods of time: 19691979 and 1986-1999 (Figs. 4 and 5). The decade of the 1970s may be considered as representative of a historic phase with few fishing improvements. In contrast, the second period was characterized by the modernization of the surface fleets, since new technology and equipment were continuously brought into use onboard vessels by tuna-fishery owner companies. The limits of interpretation should also be borne in mind, due to the strong assumptions made about equilibrium conditions.

As observed in other selectivity studies, and because the logistic curve never attains the value 1.0, the fit of the logistic curve simply provides an approximation of the length under full exploitation. For both periods of time considered, the total selectivity pattern suggests that larger-sized skipjack are selected/recruited by baitboats in the fishing grounds close to Dakar, compared with the purse seine fishery.

The L50 of purse seiners remained stable around $43-44 \mathrm{~cm}$ for both periods of time (Figs. 4 and 5). The pattern of L50 is similar for baitboats $(44-45 \mathrm{~cm})$.
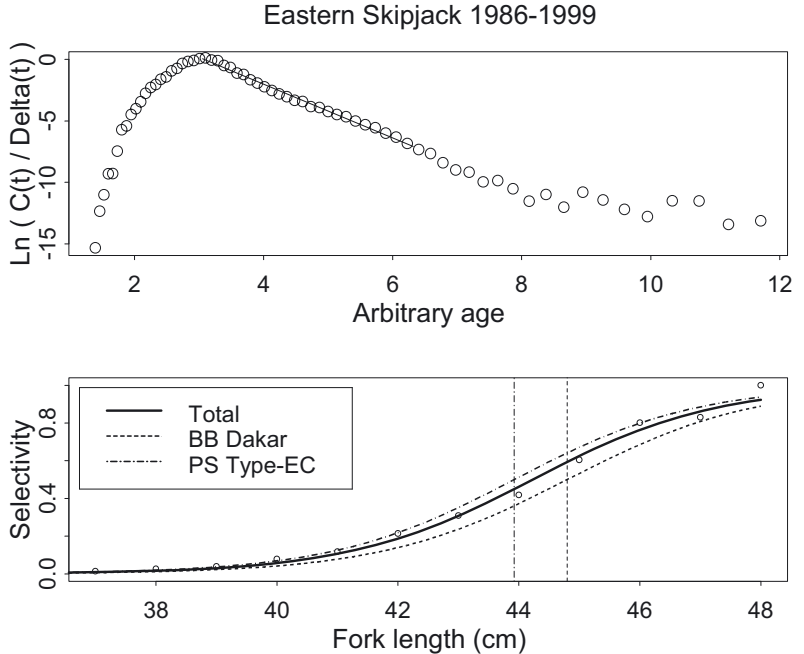

Fig. 5. Length-converted catch curve regressions (upper parts) and gear-specific selectivity patterns (baitboats operating from Dakar and EC-purse seiners and associated fleets) for the eastern Atlantic skipjack in the period (1986-1999). In contrast with the previous period of time, different fish finding devices were introduced gradually onboard tuna vessels from the mid-1980s.

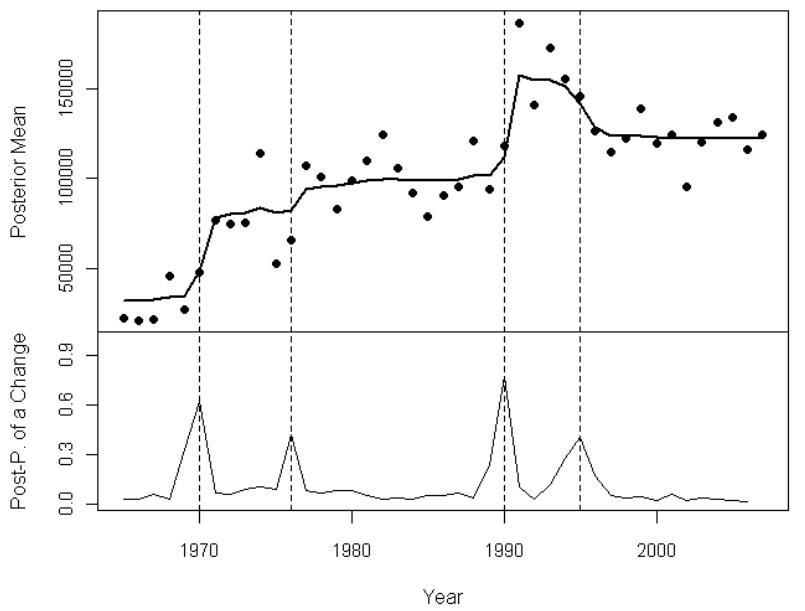

Fig. 6. Bayesian change-point analysis on the total catch of skipjack in the eastern Atlantic (1965-2007). The observed catch and the posterior mean are represented in the upper part of the figure. The posterior probability of a shift in mean value (i.e., the proportion of iterations resulting in a change point at each year) is represented in the lower part.

The application of BCP analysis to the historic catch of skipjack led to a 5-block model (Fig. 6). The observed catch of skipjack is reported over time in the eastern Atlantic Ocean, with the posterior mean value (Fig. 6 upper part). The posterior probability of change displayed in the lower part of the same figure shows the proportion of iterations resulting in a change point for each year. Figure 6 shows that the posterior probability of the change path has four peaks. The corresponding years of change were estimated to have occurred around 1970, 1976, 1990 and 1995. 


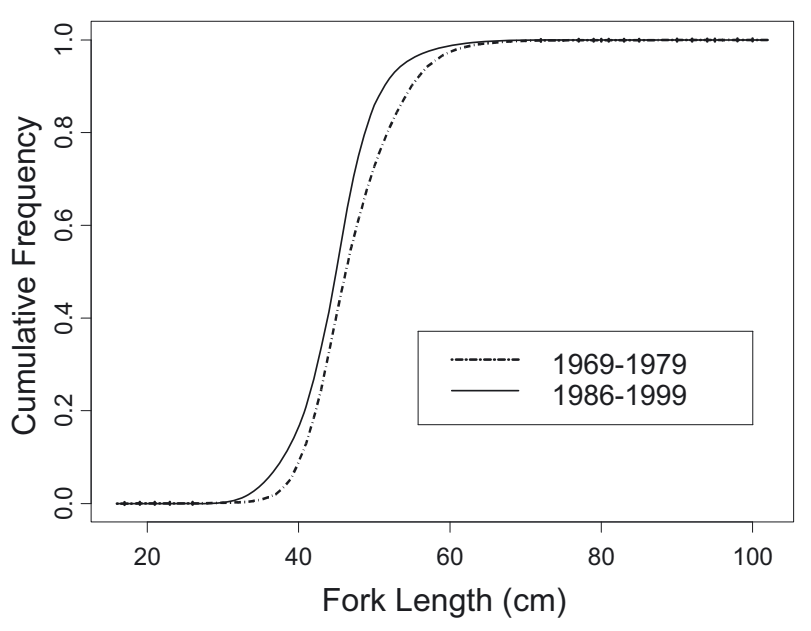

Fig. 7. Cumulative frequency of catch at length of eastern Atlantic skipjack for two contrasting periods of time (1969-1979 vs. 1986-1999).

\section{Discussion}

The comparative analysis of the historic patterns for gearspecific selectivity may be used to detect changes in targeting some commercial size categories associated with changes in fishing practices. An example of this is a decrease in selectivity over the years, which would suggest that the fleet being studied is primarily targeting young tunas. Surprisingly, this assumption is not supported by the size-frequency data since the selectivity pattern observed for the purse seine fishery remains relatively stable between the two periods considered. Even if the proportion of small fish in the total catches has increased moderately since the use of FADs (Fig. 7), the comparison of the catch-at-size of skipjack between the two periods did not highlight a qualitative change in L50 selectivity. The same conclusion can be drawn in relation to the adoption of the "associated-school fishing mode" by the pole and line fishery operating out of Dakar since the early 1980s (Fonteneau and Diouf 1994).

The apparent stability in the selectivity patterns of purse seiners might be due however to a misreport of small skipjack in the catch and/or to their absence from the port size samples. With respect to this potential bias, considerable progress has recently been made to estimate the amount and the size distribution of unreported small skipjack landed for the local market in Abidjan, Ivory Coast, as "faux-poisson". Based on scientific observer information and specific port sampling, unreported skipjack catch (average size $37 \mathrm{~cm}$ FL) has been estimated at $6600 \mathrm{t} \mathrm{year}^{-1}$ for the 1988-2007 period (Chassot et al. 2008). Nevertheless, although the ICCAT data base has been updated with this information, the reallocation of small skipjacks by stratum and fleet remains a complex procedure which might stunt any analysis attempting to discern changes in gear selectivity. There are also two possible reasons that could explain this apparent stability: (1) due to the relative viscosity of this stock (e.g., as evidenced by the low amount of mixing between eastern regions divided at $10^{\circ} \mathrm{N}$ latitude, Gaertner et al. 2008) a strategy targeting juveniles for a local portion of the stock would have little repercussion in other areas and would be difficult to detect; and (2) an increasing proportion of large fish in the catch, resulting from the expansion of the fishing areas towards the west, would compensate the increasing catch of small fish within the traditional fishing grounds.

With regards to the changes in $Z$ over time, one of the important points raised by one referee on the Gedamke and Hoenig method is that this model assumes constant recruitment. Even if the recruitment of skipjack is likely to vary from year to year, it is accepted, for biological reasons explained in the Introduction section, that recruitment variability is random rather than showing a trend over time. Additionally, under the current state of exploitation of tropical tunas, it has not been shown that recruitment varies directly with the stock size. Furthermore, the presence of a particularly large or small year-class that could affect the calculation of the population mean length has not ever been detected in the size-frequency data. The general pattern observed for mortality rate is in agreement with previous knowledge on the historic exploitation of this species. The largest values for $Z$ observed during the 1986-1999 period might coincide with a situation of full exploitation (probably reached in 1994-1995, as suggested by an analysis based on a modified version of Grainger and Garcia's index; Gaertner et al. 2001). The significant increase in mortality rates between the early 1980s and the end of the 1990s, obtained from different methods, such as tag-recovery model (Gaertner et al. 2006), and the transitional model of mean lengths (this study), corroborates this hypothesis.

Even though caution must be taken before generalizing correlation and cause-and-effect (i.e., a change in one variable is assumed to result in a change in another variable with a temporal antecedence of the cause versus the effect), there is theoretical justification in stock assessment studies to assess the degree to which total catch increases (or decreases) mortality rate. In two historic situations, the mean shift in skipjack catch led clearly to concomitant changes in mortality rates 3-4 years later. This delay reflects the range of the age classes that were fully fished. The increase in $Z$, estimated to have occurred in 1979-1980, likely resulted from the increase in catch detected in 1976 by the BCP model (the annual variability observed in the mid-1970s suggests that it would have been difficult to detect such a shift in catch by a simple screening of the time series). The second situation concerns the decrease in mortality rate observed after 1999 , which was caused by the decline in catch after 1995.

Contrary to this, even though the transitional model was set up to search for a change in mortality prior to the time-series of mean length data (as suggested by Gedamke and Hoenig 2006), the first change point in catch (1970) was not followed three years later by a concomitant change in the transitional model of mean length. For the other cases, the insufficient statistical linkage between catch and $Z$ might be due to the variability of the data for the blocks of years considered. Thus, for these cases, not all the criteria for making causal assertions were met (i.e., a significant change point was detected for one variable only) but there was cumulative evidence favoring the research hypothesis (i.e., the time lag and the pattern of covariation were in agreement with the previous results). For example, the shift in $Z$ predicted by the transitional 
model in 1985 might be linked with the increase in catch observed in 1981-1982 (although the BCP model failed to detect such a change, possibly due to the large variability of the catch data in the early 1980s). Along these lines, the large posterior probability of the change in catch that occurred in 1990 was not associated with a significant increase in mortality rate from the best transitional model. However, the second best model with 4 breaking points detected a breaking date at 1992 (Table 1). It should be noted that a moderate increase in $Z$ is suggested by the simple Beverton-Holt estimator which rose in 1993 (Fig. 3).

The evolution of mortality rates for skipjack in the eastern Atlantic Ocean is in agreement with general expectations related with the increase in fishing pressure until the late 1990s. As stated in the Introduction, many technological factors have contributed to the increase in purse-seiner fishing efficiency. However, owing to the individual variability in the dates of introduction of new equipment onboard fleets, the overlap between installation periods, and the combined effects of certain innovations, it has been difficult to accurately appraise the contribution of each separate factor on the increasing mortality rate (Gaertner and Pallares 2002).

Among these various innovations, the massive use of FAD since the late 1980s (Ariz et al. 1999) has been considered as one of the most relevant. However, real progress only occurred when fishers were able to implement electronic technology on their drifting FAD in order to locate them easily at a great distance. The use of GPS positioning buoys since $1997-$ 1998, particularly the Ariane type, which progressively substituted the Gonio system introduced in the early 1990s, can be considered as a significant step forward in the development of purse-seine fishing power. In the early 2000s, tracking buoys that transmit continuous buoy trajectories to a computer interface onboard the vessel and sonar transmitting satellite buoys, equipped with solar panels, became very useful for maximizing "search" time, or time spent traveling to and assessing FAD (Itano 2003; Moreno et al. 2007).

In addition, it was shown that the combined effects of certain fish finding devices (e.g., sonar and echo-sounder), used while fishing around FAD (Gaertner and Pallares 2002), were clearly associated with an increase catchability of skipjack, as well as juveniles of yellowfin (Thunnus albacares) and bigeye tuna (Thunnus obesus). Sonar has been used onboard tuna boats for a long period of time now but its fundamental roles, which are to aid in deciding net settings and to guide the captain during the encircling of the school, gradually increased over the years, as recognized by skippers responding to questions on this point (Gaertner et al. 2000).

The decrease in $Z$ observed for the last part of the studied period should be partially due to a regular decrease in fishing pressure, since the nominal fishing effort of European and associated purse seiners decreased regularly since the late 1990s (Pianet et al. 2008). To assess this assumption, we compared the historic path in mortality rates for the three tropical tuna species using the simple Beverton-Holt mortality estimator (we focused more on the comparison of species-mortality trends than on the detection on specific breaking dates). As for skipjack, $L c$ was fixed at $46 \mathrm{~cm}$ and we simplified further by assuming a von Bertalanffy growth curve for yellowfin and

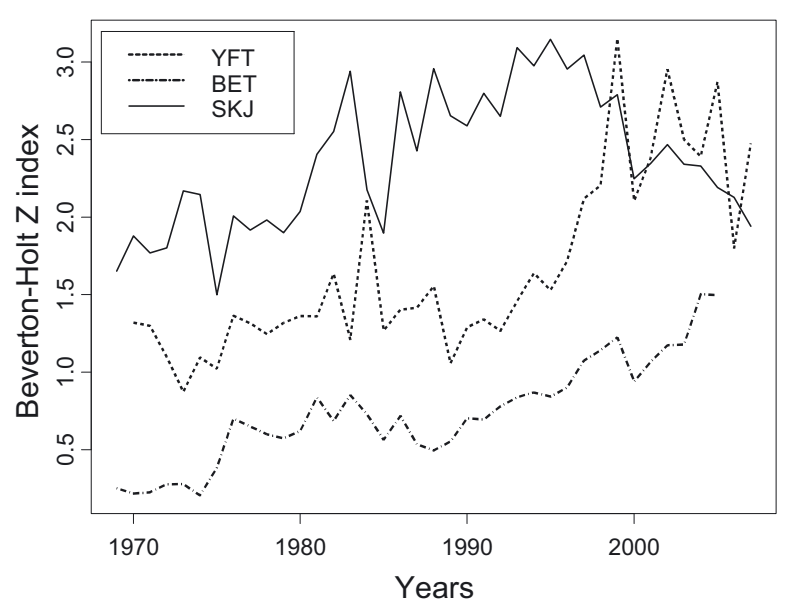

Fig. 8. Comparative analysis of the changes over time of the Beverton and Holt's mortality rate $(Z)$, for the three tropical tuna species in the eastern Atlantic. YFT = yellowfin, BET = bigeye, SKJ = skipjack.

bigeye (even though a two-stanza growth curve seems more realistic for both species) with $L \infty$ and $K$ fixed at $151.7 \mathrm{~cm}$ and 0.728 year $^{-1}$, and $217.3 \mathrm{~cm}$ and 0.18 year $^{-1}$, respectively.

Figure 8 shows a decline in apparent $Z$ over time was not clearly evidenced for the other two tropical tuna species. This discrepancy in the historic pattern of $Z$ between the three species of tunas suggests that the decreasing trend observed for skipjack probably results from a combination of the decrease in nominal effort of the EU and associated purse seiners and in the impact of the moratoria on FAD fishing (specifically large for skipjack; Goujon and Labaisse-Bodilis 2001). It must be noted, however, that this trend could have been stunted by the development of FAD fishing in the Ghanaian surface fishery (Bannerman and Bard 2001).

In addition to these considerations, it must be stressed that the association with drifting FADs may have a negative effect on the biology (food intake, growth rate, fish plumpness) and on the ecology (displacement rate, movement orientation) of skipjack (i.e., the "ecological trap" concept; Hallier and Gaertner 2008). The patterns found by these authors suggest that tuna may be trapped into a maladaptive behavioral strategy caused by the massive use of drifting FAD in the tropical Ocean. However, in a situation of moderate fishing intensity (or with a reduction of the FAD fishing strategy), this negative impact might be reduced because the proportion of the fish attracted to areas of low quality habitat will be compensated for by the fish choosing areas of high quality habitat.

Acknowledgements. The author thanks the two anonymous referees for their constructive comments.

\section{References}

Ariz J., Delgado A., Fonteneau A., Gonzalez Costas F., Pallares P., 1999, Logs and tunas in the eastern Tropical Atlantic. A review of present knowledge and uncertainties. In: Scott M.D., Bayliff W.H., Lennert-Cody C.E., Schaefer K.M. (Eds.). Proc. International Workshop on fishing for tunas associated with 
floating objects, La Jolla, CA, February 11-13, 1992. Inter-Am. Trop. Tuna Comm., Spec. Rep. 11 21-65.

Bannerman P.O., Bard F.-X., 2001, Recent changes in exploitation patterns of tunas in the Ghanaian fishery and their effects on commercial catch at size. Col. Vol. Sci. Pap. ICCAT 52, pp. 466-479

Bard F.-X., Antoine L., 1986, Croissance du listao (Katsuwonus pelamis) dans l'Atlantique est. In: Symons PEK, Miyake PM, Sakagawa GT (Eds.). Proc. ICCAT Conf. Int. Skipjack Year Prog. ICCAT Madrid, pp. 301-308.

Barry D., Hartigan J.A., 1993, A Bayesian analysis for change point problems. J. Am. Stat. Assoc. 88, 309-319.

Beverton R.J.H., Holt S.J., 1956, A review of methods for estimating mortality rates in exploited fish populations with special reference to sources of bias in catch sampling. Rapp. P.-V. Réun. CIEM 140, 67-83.

Burnham K.P., Anderson D.R., 2002, Model selection and inference: a practical information-theoretic approach, 2nd edition. SpringerVerlag, New York.

Cayré P., Farrugio H., 1986, Biologie de la reproduction du listao (Katsuwonus pelamis) de l'océan Atlantique. In: Symons, P.E.K., Miyake, P.M., Sakagawa, G.T. (Eds.), Proc. ICCAT conference on the international skipjack year program, Madrid, pp. 252-272.

Chassot E., Amande M.J., Chavance P., Pianet R., Dédo R.G., 2008, A preliminary attempt to estimate tuna discards and by-catch in the French purse seine fishery of the eastern Atlantic Ocean. ICCAT Sci. doc. SCRS/2008/117.

Erdman C., Emerson W.J., 2007, bcp: An R package for performing a Bayesian analysis of change point problems. J. Stat. Software 23, 1-13, http://www.jstatsoft.org/

Fonteneau A., Diouf T., 1994, An efficient way of bait-fishing for tunas recently developed in Senegal. Aquat. Living Resour. 7, 139151.

Fonteneau A., Gaertner D., Nordstrom V., 1999, An overview of problems in the catch per unit of effort and abundance relationship for the tropical purse seine fisheries. Col. Vol. Sci. Pap. ICCAT 49, pp. 258-278.

Gaertner D., Ariz J., Hallier J.P., Herrera Armas M.A., 2000, Le point de vue des pêcheurs thoniers à la senne sur l'augmentation des prises de patudo dans l'Atlantique Est et sur les conditions d'utilisation du sonar. Col. Vol. Sci. Pap. ICCAT 51, pp. 553570.

Gaertner D., Bard F.-X., Hallier J.-P., 2006, Are natural and fishing mortalities comparable from tropical tunas? A multispecies approach with tagging data. Col. Vol. Sci. Pap. ICCAT 59, 421-430.

Gaertner D., Delgado de Molina A., Ariz J., Pianet R., Hallier J.-P., 2008, Variability of the growth parameters of the skipjack tuna (Katsuwonus pelamis) among areas in the eastern Atlantic: analysis from tagging data within a meta-analysis approach. Aquat. Living Resour. 21, 349-356.
Gaertner D., Fonteneau A., Laloë F., 2001, Approximate estimate of the maximum sustainable yield from catch data without detailed effort information: application to tuna fisheries. Aquat. Living Resour. 14, 1-9.

Gaertner D., Laloe F., 1986, Etude biométrique de la taille à première maturité sexuelle de Geryon maritae Manning et Holthuis, 1981 du Sénégal. Oceanol. Acta 9, 479-487.

Gaertner D., Pallares P., 2002, The European Union Research Project, Efficiency of Tuna Purse-Seiners and Effective Effort (ESTHER): Scientific report of project. SCTB15, Working Paper FTWG-3.

Gedamke T., Hoenig J. M., 2006, Estimating mortality from mean length data in nonequilibrium situations, with application to the assessment of goosefish. Trans. Am. Fish. Soc. 135, 476-487.

Goujon M., Labaisse-Bodilis C., 2001, Effets des plans de protection des thonidés de l'Atlantique depuis 1997 d'après les observations faites sur les thoniers senneurs gérés par les armements Français. Col. Vol. Sci. Pap. ICCAT 52, pp. 575-589.

Hallier J.-P., Gaertner D., 2008, Drifting fish aggregation devices could act as an ecological trap for tropical tunas. Mar. Ecol. Prog. Ser. 353, 255-264.

Hervé A., Bard F.X., Gonzalez Costas F., 1991, Facteurs d'accroissement potentiels de la puissance de pêche des senneurs tropicaux français et espagnols entre 1985 et 1989. Col. Vol. Sci. Pap. ICCAT 35, pp. 8-13.

Itano D., 2003, Documentation and classification of fishing gear and technology on board tuna purse seine vessels. SCTB16 Working Paper FTWG-3.

Moreno G., Dagorn L., Sancho G., Garcia D., Itano D., 2007, Using local ecological knowledge (LEK) to provide insight on the tuna purse seine fleets of the Indian Ocean useful for management. Aquat. Living Resour. 20, 367-376.

Morón J., Areso J., Pallarés P. 2001, Statistics and technical information about the Spanish purse-seine fleet in the Pacific. 14th Standing Committee on Tuna and Billfish, Working Paper FTWG-11.

Pianet R., Norström V., Dewals P., Delgado A., Ariz J., Saralde R., Gnegoury Dédo R., Diatta, Y., 2008, Statistiques de la pêcherie thonière européenne et assimilée durant la période 1991-2006. Col. Vol. Sci. Pap. ICCAT 62, pp. 289-314.

Restrepo V.R., Ortiz de Urbina J., Fromentin J.-M., Arrizabalaga H., 2007, Estimates of selectivity from eastern Atlantic bluefin tuna from catch curves. Col. Vol. Sci. Pap. ICCAT 60, pp. 937-948.

Sparre P., Ursin E., Venema S.C., 1989, Introduction to tropical fish stock assessment. Part 1 Manual, FAO Fish. Tech. Pap. $\mathrm{N}^{\circ}$ 306.1, Rome FAO.

Ssentongo G.W., Larkin P.A., 1973, Some simple methods for estimating mortality rates of exploited fish populations. J. Fish. Res. Board Can. 30, 695-698. 